\title{
Asset Integrity Safety and Organisational Health in the Nigerian Petroleum Industry
}

\author{
Edward-Odoi, Chigozie Akawho Dennis \\ Faculty of Management Sciences, University of Port Harcourt, Nigeria \\ Prof. Jaja, Seth Accra \\ Faculty of Management Sciences, Rivers State University of Sciences and Technology, Nigeria
}

\begin{abstract}
This study investigated the relationship between asset integrity safety and organisational health in the Nigerian Petroleum Industry. The research design adopted the cross sectional survey and utilized the nonprobability purposive sampling technique in selecting the sample of 130 managers that responded to the statistical questionnaire survey. The study employed the self-administered questionnaire to obtain primary data, while secondary data were collected from the Department of Petroleum Resources (DPR) and the HSE Departments of the sampled companies. The SPSS Version 20 was used in analysing the data. Results show that asset integrity safety (WSP) has a significant relationship with organisational health, as the null hypotheses were all rejected. Therefore, based on the findings, it is recommended that the sector/industry management should adhere more strictly to benchmarked HSE compliance injunctions for corporate business continuity and environmental sustainability.
\end{abstract}

Keywords: Asset integrity safety, organizational health, adaptation, cohesiveness

\section{INTRODUCTION}

Working safe in all aspects of organizational life has remained a challenge in many respects to the survival of firms either as a small enterprise or large complex organization. This requirement had taken priority in organizations boardroom debates and daily routine operational evangelism to such extent that Health, Safety and Environment Integrated Management Systems (HSE-IMS) practices is assuming a global appeal to all concerns in the petroleum sectors of nations. Analysts have philosophized particularly on the strands of Health, Safety and Environment concerns which is a basic segment of Workplace Safety Practices. Working safe is not just a requirement but a companywide culture that touches on all areas of firms' operations. The assumption for this culture drive is basically a regulatory mechanism for non-hazardous work life but the major concern remains that such cherished and eventually acculturated requirement must be seen in the light of good organizational healthiness, since only a healthy organisation can achieve and sustain successful business enterprising, in all ramifications, especially cost wise. Often, Organisations are found to professedly implement practices, policies and procedures to improve their performance, while apparently very unaware of the context impact of imperative workplace safety practices vis-à-vis the implications thereof. The impact of this knowledge gap, apparently based on an inadvertent strategic organisational ignorance, arguably constrains the leadership from its expected statutory role effectiveness and efficiency; and consequently, affecting its status organisational health. This phenomenal gap creates an impact which cannot ordinarily be wished away; because, as Richardson (2007) asserts, "leadership is cause; every other thing is effect". And more so, since strategic leadership is not only driven by knowledge but it is itself, basically, knowledge based. Certainly, strategic successful organisational performance sustainability is essentially a function of the knowledge adequacy that abounds within and acquired by the workforce, which calls the attention of Top-Management and indeed, all and sundry, to prospective/incident deficiencies with ease and relatively prescribes proactive remedies through smooth sailing appeals. Obviously, when the worker is adequately knowledgeable about its organisation's safety systems/functions, he/she adapts easily to the organisational cultural practices and compliance requirements. The outcome result is an improved organisation with good organisational health, which is a strategic organisational benefit. 
Other researchers have studied context organisational health issues and have equally analysed corporate organisational climate from the perspective of other predictor variables and dimensions. Nevertheless, this study has contributed in filling the knowledge gap by investigating organisational health from the perspective of yet another strategic predictor variable, 'Workplace Safety Practises', through adequate knowledge transfer vis-à-vis the adaptation and cohesiveness of organisational leadership, in the Nigerian Petroleum Industry. This status shall be established from tracked operational essences from the Health, Safety and Environment (HSE) window, in the attempt to appraise organisational performance in this industry. Obviously, this background precisely underpins the importance, as well as vividly placing the necessity for this study in clear perspective. Every organisation strives to attain an internal work environment that can be described as good organisational health. The organisational health permits the effective pursuit and attainment of its goals. Again, the organisational health permits internal flexibility and external adaptability of the organization. For instance, the resilience capacity of any organization depends on its adaptability to, and state awareness on environmental factors (Riolli and Savcki, 2003 and Sevile, 2011). It presupposes that the organisational health is a cardinal factor that facilitates its readiness to attain its goals. This rests on the organisational ability to adjust to environmental perturbations, being aware of its vulnerabilities in the context of survival. Thus, in order to achieve an internal work environment that can foster good organisational health, from the safety point of view, the leadership must be able to identify the HSE practices boundaries and cohesively adapt adequate and peculiar compliance strategies to drive it adequately.

Studies have shown that considerable relevance exists on how organisational health and resilience capacity impact on organisational performance. For instance, Aguh (2006) is doggedly emphatic that organisations that are replete with characteristic operational maladies are symptomatic of corporate illnesses. In other words, such organisations with context health issues are incapable of determining their performance quotient; and by extension, unable to assure their corporate health because of the preponderance of corporate governmental issues and disarray, low degrees of assurance and profitability and high turnover among dedicated workers, Lencioni (2012). This argument therefore, obviously emphasizes the inevitable necessity for the organisational health of firms to be effectively tracked because, according to Lencioni (2012), it contributes the "healthy attributes" required for a healthy organisation that complements the "smart" attributes for a sustained organisational success. Lencioni (2012) also argues that most executives shy away from recognizing, let alone discussing the "healthy attributes" even though they cannot deny their existence vis-à-vis their characteristic corporate negative effect on the success and sustainability of the particular organisation from its inevitable status classification as healthy specie. It could hence be deduced that the dependent variable for this study (Organisational Health) is not only necessary but a very important requirement for the assessment of the organisational health status of a typical organisation.

Leading organisations across the globe today (including those in the petroleum sector) are said to have realized the importance of asset integrity safety vis-à-vis the necessity of the implicit business sustaining activities and are spiritedly making concerted efforts to foster HSE practices in all areas of their operation. The implication here is that the leadership must ensure that individuals embrace, adapt and comply with the injunctions of safety practices, systems/processes within the workplace. From the foregoing, one is inclined to concurring that organisational health has been identified to be the major issue at the root of organisational failures of firms within the Petroleum Industry. Hence, compliance with strategic asset integrity Safety Practices has been prospected as the remedy to posit relative complimentary cures; and consequently, the necessity for this study.

\subsection{Aim of the Study}

The main purpose of this study is to examine the relationship between asset integrity safety and organisational health.

\subsection{Research Question}

The following research question is therefore pertinent to this study: -

What is the relationship between asset integrity safety and organizational health? 


\section{REVIEW OF RELATED LiTERATURE}

\subsection{Asset Integrity Safety (AIS)}

The term 'Industrial Safety' refers to the safety activities and measures designed and employed in 'accessing, processing and checking' (apc) installed asset integrity, tracking operational deviations or non-conformances/noncompliance thereof, with a view to enforcing statutory compliance to standards and benchmarks. Asset Integrity Safety can thus be appreciated as a set of safety assurance practices tracking measures detailing HSE activities that are designed to track the integrity of installed industrial assets and facilities' operations/operational health to ensure compliance with statutory safety benchmarks as well as relative investment sustainability. Asset integrity safety knowledge is concerned with ensuring that the people, systems, processes and resources that deliver/sustain integrity are in place, in use and will perform when required over the whole lifecycle of the asset (Centre for Chemical Process Safety, 2007). Baker (2007) maintained that, effective asset integrity management programme is a prerequisite for continued safe operation of any chemical process plant. However, the challenge is not only to ensure that containment systems remain intact through the use of appropriate inspection, testing, maintenance and repair strategies but that those strategies are implemented by competent and motivated personnel; and that, they remain suited to the equipment age and condition, over time. Obviously, such competent or knowledgeable personnel, appropriate professional competence and enduring motivation can of course be achieved only through adequate and appropriate knowledge transfer strategy, whereby the organisational systems/subsystems, processes and operating modus operandi are duly and diligently conveyed to the operatives using formal modes. In other words, the emphasis here is in appreciating cum delivering adequate knowledge of the appropriateness of the organisation's asset integrity safety practices or measures to the ordinary operative such that Top-Management shall be convinced to buy into the necessity and value for integrating this strategy in the corporate managerial undertaking as a strategic critical corporate cost saving venture and; by lateral extrapolation, an implicitly recommended good organisational health practice for the organisation. As managers, the aptness of the knowledge transfer project with respect to consequences for brute neglect and/or benefits for the organisation appropriately imbibing and internalising them is certainly the point of departure from routine operational activities tracking consideration that makes sense for managing and thus underlines the importance of this dimension.

The prevention of accident is virtually the cardinal purpose and essence of safety in whatever definition or manifestation. Matthias (1973), Oyolu (1993), Agbakolam (1993), Captain-Briggs (1994), Klinoff (2009) and Jain \& Rao (2009) are all in agreement that effective accident prevention strategies target zero occurrences or a substantial near zero case; that is, zero tolerance, as much as reasonably practicable. Accident, as an unplanned event, which disrupts the completion of any activity, is invariably preceded by a combination of unsafe acts, untracked near misses and/or unsafe conditions. The loss due to accidents is colossal in the form of pain, loss of life and earning capacity. Pain and suffering of the injured as well as the emotional loss to the victims of the fatalities and accidents causing disfigurement or disabilities are impossible to be summed up or evaluated. Accident prevention must be taken seriously in industry as the necessity for accident prevention is generally accounted for by both humanitarian aspects and economic considerations. The occurrence of an accident always results in a number of effects that constitute various and varying degrees of inconveniences to the victim, a number of people or organisations, including pain to victim(s) due to injury sustained, mental agony to family members, loss of productive worker suffered by the organisation, loss of time of other workers who undertake to help the injured, management's bearing of financial losses emanating from payment of compensation and medical expenses, and society's contending with the social burden of usually supporting the injured worker's family, referred to as 'second degree invalids'. This social burden is, itself, a compact basket that translates into different subheads including financial, physical, mental and psychological manifestations and traumas, among others. The intent of an incident investigation, state Captain-Briggs (1994) and Jain \& Rao (2009) et al, is "to learn from past experiences and thus avoid repeating past mistakes". Consequently, incident investigation and analysis constitute the process of "identifying the underlying causes of incidents and implementing steps to prevent similar events from occurring" in future.

\subsection{Organisational Health}

Organisational Health $(\mathrm{OH})$ is the criterion variable for this study. According to Alagah (2014), scholars in this field have posited that it is of critical essence that knowledge creation be anchored on 
sound, theoretical base. They argued that it strengthens the experiential belief that arises from such strategic conjectures. Also, recent scholarly work by safety engineering scholars and industry practitioners seem to have focused on the domain of workplace safety practices and its place in the general management field; e.g., Sharma and Christian (1999); Brush et al. (2003) and Ketchen (2003), are in agreement with Alagah (2014) on this issue. Several researchers commented in Alagah (2014), on the strategy prescribed by statutory tracking philosophy, applicable in routine knowledge construct doctrine, which is consistent with its peculiar tracking injunction. Their summary position support the fact that safety engineers and contemporary HSE experts alike, in the attempt to establish legitimacy, have generally engaged in constant evaluation and re-evaluation of the workplace safety practices paradigm as to confirm its place among related paradigms in this field of knowledge enquiry (Heinrich, 1950; Deming \& Edwards, 1986; Joel, 1992; Hunt, 1993; Thomas, 1996; Gilbert, 2007; McKinnon, 2007; BLS, 2009), cited in Alagah (2014).

Also, looking at organisational health from the point of view of some comparative principles, the Swiss writer and philosopher, Henri Frédéric Amiel (1821-1881), once muted that: "Health is the first of all liberties, and happiness gives us the energy which is the basis of health". Over forty five years later, the Austrian-born U. S. educator and researcher, Ivan Illich (1926-2002), reinforced Henri's philosophical eulogy, strongly positing that: "Healthy people are those who live in healthy homes on a healthy diet; in an environment equally fit for birth, growth, work, healing, and dying...Healthy people need no bureaucratic interference to mate, give birth, share the human condition, and die". Obviously, both sages were aware and presumably versed in both classical and contemporary human health dynamics even within an organisational cum environmental setting. Perhaps, contrasted with their own observation of probably agonizing cases of avoidable waste of human capital in the industrial factories as expectedly witnessed in their respective eras, they became compelled to draw government and public attention to the need to reflect rather more strongly on the subject of qualitative healthiness generally, and industrial health, specifically, in the effort to emphasize the basic importance of the corporate health of organisations to facilitate its characteristic stance for readiness to compete generally. It is a concrete fact that contemporary strategies emphasize heavily on the critical health and the well-being of not only human beings but extensively also to virtually everything, living and non-living, including the organisation per se. Their worries and fears constitute what has broadly transformed the development and advancement of contemporary occupational health issues.

Patrick Lencioni believes that "the single greatest advantage any company can achieve is organisational health". Consequently, he is optimistic that "organisational health will one day surpass all other disciplines in business as the greatest opportunity for improvement and competitive advantage" Lencioni (2012). In his book, "The Advantage: why organisational health trumps everything else in business", he made a polemical case for organisational health, arguing that while all organisations possess the decision sciences 'smart' attributes of strategy, marketing, finance and technology, referred to as classic fundamentals of business that constitute one half of the characteristic requirement equation that is critical to the success of an organisation, the other half, which is largely neglected, is about being healthy vis-à-vis the 'healthy' attributes. He contends that minimal politics and confusion, high degrees of morale and productivity and very low turnover among good employees constitute the other half of the two requirements for an organisation's success. In other words, most successful organisations are not necessarily healthy whereas any organisation, (devoid of contending/destructive political manoeuvring, strategic decision confusion, conscientious high degrees of morale and productivity, and compelling high turnover among good employees) which, inadvertently qualifies as a healthy organisation, must of necessity stake statutory and strategic business successes. He labels organisational health as fraught with the potential for subjective and awkward conversations, which most business executives avoid; instead, preferring the measurable, objective, relatively safe and predictable, and data-driven world of organisational intelligence only, which is obviously the 'smart' side of the equation for organisational success. The opportunities for improvement and competitive advantage offered in the 'smart' classic areas of business (or the other half of the two requirements for business success) he argues, in spite of all the attention they receive, are incremental and at best, fleeting. It is apparent that the arguments in this perspective clearly presents that every organisation requires two characteristics - intelligence ('smart' part) and health to sustain successfully. Indeed, from Lencioni's point of view, organisational health is given more weight and can be better appreciated from the perspectives of cultural values and strategic aspiration. In this realm therefore, organisational health can logically be seen/defined as the complimentary half of the characteristic requirements for an organisation's business success, which is driven by a culture 
of aspirational values, intentionally managed into the organisation. Lencioni, while not out rightly dismissing smartness as unimportant and necessary, emphatically concludes that "the seminal difference between successful companies and mediocre or unsuccessful ones has little, if anything, to do with what they know or how smart they are; it has everything to do with how healthy they are".

\subsubsection{Adaptation}

Adaptation is defined as "the ability to tolerate stress and maintain stability while changing to meet the unique needs of their stake holders" (OHDDC, 2008). This definition is popular and adopted by many researchers considering the enormous resources expended by its proponents in their land mark research in Organisational Health. However, for the purpose of this study, and in keeping with the tenets of our focus, an imperative modification to this definition has been introduced to address identified salient areas. Consequently, in the context of this study, adaptation is defined as the ability of the managerial leadership (representing the organisational members or groups) and the organisation itself to 'mutually tolerate each other' and still carry on the organisation's business to sustain its focus, while simultaneously addressing organisational challenges that may arise from both internal and external demands; in other words, endogenous and exogenous factors. As it is obvious, the key emphases of this definition are 'ability of the organisation', measured from 'mutual tolerance of stress', 'maintenance of stability' and 'confronting and containing both endogenous and exogenous organisational challenges', respectively. Any emerging relationship between adaptation and organisational health therefore, must necessarily be appreciated or consummated from the perspectives of these critical emphases. Of a truth, adaptation is contextually about the human attitudinal disposition juxtaposed with their characteristic response to changing organisational (climatic and/or environmental) disposition.

Organizational adaptation varies along several dimensions including, for example, the extent to which changes in an organization involve core features (e.g. technology) or characteristics that are more peripheral (e.g. size of advisory board) and the time required for changes to occur (Hannan and Freeman, 1984). In my view, one of the most important adaptations of mentally healthy organizations concerns the adjustments they make in their staff or personnel patterns. The importance of personnel changes (or adaptation) is that professionals and others in the field of mental health bring with them to organizations certain well-developed ideologies and beliefs concerning the causes of and treatment for health problems relative to their particular organisation. In other words, requirements to hire staff members with particular educational training may lead to changes in organizational ideology. In turn, the ideology of the dominant coalition in mentally healthy organizations may play a key role in the selection and use of modification approaches (Hasenfeld, 1983). Over the years, of course, various professional groups, including psychiatrists, psychologists and social workers, have attempted to protect their interests in the mental health field by influencing licensing and funding agencies to establish staffing criteria that are favourable to their members. In short, the adaptation of mental health organizations to rules established by powerful interest groups and organizations in their environment is likely to have consequences for several key aspects of their work, particularly their interaction with clients. In the same vein, managers strive to convince their workforce to imbibe instituted organisational changes through strategic adaptation. Thus we hypothesize that:

$\mathbf{H O}_{1}$ : There is no significant relationship between asset integrity safety and adaptation

\subsubsection{Cohesiveness}

According to OHDDC (2008), cohesiveness is the state when persons or groups have a clear sense of identity, are attracted to membership, want to stay, and are willing to influence and to be influenced. Similarly, cohesiveness can be seen as the extent to which team members stick together and remain united in the pursuit of a common goal. A team is said to be in a state of cohesion when its members possess bonds linking them to one another and to the team as a whole. Members of a highly cohesive team focus on the process, not the person; they respect everyone in the team, assuming good motives; and they fully commit to team decisions and strategies, creating accountability among the team. Morale is also higher in cohesive teams because of increased team member communication, friendly team environment, loyalty and team member contribution in the decision-making process. Successful business strategies are usually carried out by an effective team with a high level of team cohesiveness. Highly cohesive teams are more committed to the goals and activities, are happy when the team succeeds and feel part of something significant, all of which increases self-esteem which, in turn, increases performance. 
They are satisfied that the organisational goal is paramount and must be achieved first; hence, voluntarily and willingly, they subsume their individual goals to achieve them later. Strategic cohesiveness implies that this state is viewed as essential for maintaining the organizational structure for effective functioning vis-à-vis organisational performance; and by extension, organisational healthiness. Thus, this can be seen as a measure of the state of employee acceptance of the organisation's position dynamics whereby there can be said to be understanding and synergy (even in terms of the return on investment -ROI- principle), as a function of the produced number of barrels of oil and associated petroleum products, consistent with the policy on zero (or, as much as reasonably practicable) minimal occurrence of operational accidents/incidents, inclusive of loss time injuries (LTIs) per given production period. Cohesiveness is a policy emphasis phenomenon, which is about growth; and it engenders it strategically. Growth is an index depicting development. The Microsoft Encarta Dictionary (2009) defines growth as a "growing process - the process of becoming larger and more mature through natural development". Indeed, the complimentary thesaurus version specifically describes growth as "development". Thus we hypothesize that:

$\mathbf{H O}_{2}$ : There is no significant relationship between asset integrity safety and cohesiveness

\section{Materials AND Methods}

\subsection{Research Design}

The research design adopted in this study is the cross-sectional survey. This enabled the research visà-vis the researcher to collect data from a wide range of study elements that enhanced the generalization of the research outcome. This choice is also determined by the study setting, the nature and type of study (Okpu \& Kpakol, 2015; Baridam, 2008). This study employed a combination of the technique of self-administered questionnaire and collection of incident statistics records from pertinent secondary sources to gather data on the phenomenon under investigation, including executive reviews with the management representatives of the Human Resources and the HSE departments of the sampled companies and the industry supervisor, the Department of Petroleum Resources (DPR).

\subsection{The Population for the Study}

The population for this study consists of all the firms within the four sectors in the Nigeria Petroleum Industry; namely: Exploration \& Production, Drilling, Marketing and Services. From the 2011 edition of the directory of the Nigerian Oil and Gas Industry, a total of 565 companies have been listed. However, this population is hardly accessible; more so, because 84 operators and partner companies in the list were reportedly still in the licensing rounds from 2005, 2006 and 2007 respectively, implying that they were not yet statutorily fully listed, but were only granted interim listing at the time. In other words, the population for this study was eventually determined using the convenience sampling strategy employing the DPR standard of industry strategic activities' KPI rating.

\subsection{Sample and Sampling Procedure}

The study adopted the non-probability sampling procedure, employing the purposive sampling technique (Baridam, 2008). The sample size consequently consists of twenty-five (25) departments drawn from the study population of 5 companies in the Exploration and Production sector. One of the downsides of utilizing purposive sampling technique is that the population parameters cannot be estimated from the values of the characteristics obtained from the sample. Secondly, the results will not be generalized.

\subsection{Data Collection Method}

The data for this research was obtained from both primary and secondary sources, employing the strategies of questionnaire administration and incident statistics record. The primary source of data was the self-administered questionnaire. The researcher designed questionnaire which was administered at the selected sample/study locations.

\subsection{Reliability of the Measuring Instrument}

The reliability of the instrument was determined using the test-retest method. The scores derived from the two administrations of the instrument were correlated using Pearson correlation statistical. Table 1 below, computed using the Statistical Package for Social Sciences (SPSS). Consistent with Barclay, Higgins and Thompson (1995), this result is considered high enough, to confirm the reliability of the instrument. 
Table1. Results of the Reliability Analysis

\begin{tabular}{|c|l|c|c|}
\hline S/N & \multicolumn{1}{|c|}{ Variables } & Number Of Items & R Coefficients \\
\hline 1 & Asset Integrity Safety & 14 & 0.726 \\
\hline 2 & Adaptation & 5 & 0.803 \\
\hline 3 & Cohesiveness & 9 & 0.725 \\
\hline
\end{tabular}

\section{Results}

\subsection{Correlation Analysis and Decision Rules}

The two hypotheses, which dealt with the relationship characteristics between predictor variable (Asset Integrity Safety) and the measures of the organizational health (adaptation and cohesiveness), were thus analysed using the Spearman Rank Order Correlation Coefficient statistical tool. The Spearman Rank Correlation Coefficient Rho is computed at the 0.05 level of significance. The decision rule states that: "At the 0.05 level of significance,

1. Reject $\mathrm{H}_{\mathrm{O}}$ if $\mathrm{P}<0.05$;

2. Accept $\mathrm{HO}$ if $\mathrm{P} \geq 0.05$.

\subsection{Hypothesis 1 [HO1]}

There is no significant relationship between Asset Integrity Safety and Adaptation in the Nigerian Petroleum Industry.

Table2. Showing computed relationship between Asset Integrity Safety and Adaptation in the Nigerian Petroleum Industry.

\begin{tabular}{|c|c|c|c|c|}
\hline & & & Assetintegritysafety & Adaptation \\
\hline \multirow{6}{*}{ Spearman's rho } & \multirow{3}{*}{ Assetintegritysafety } & Correlation Coefficient & 1.000 & 0.649 \\
\hline & & Sig. (2-tailed) & & 0.040 \\
\hline & & $\mathrm{N}$ & 130 & 130 \\
\hline & \multirow{3}{*}{ Adaptation } & Correlation Coefficient & 0.649 & 1.000 \\
\hline & & Sig. (2-tailed) & 0.040 & \\
\hline & & $\mathrm{N}$ & 130 & 130 \\
\hline \multicolumn{2}{|l|}{ Decision: } & \multicolumn{3}{|l|}{ Reject $\mathbf{H}_{\mathbf{O 1}}$} \\
\hline
\end{tabular}

Source: Survey data, 2016

Table 2 shows the result of the correlation using the Spearman Rank Correlation Coefficient tool. From the result, it is shown that a significant relationship exists between asset integrity safety and adaptation. Asset integrity safety showed a strong positive relationship with adaptation, with Rho = 0.649. The relationship is significant at $\mathrm{p}=0.04<0.05$ significant level. From this outcome, the hypothesized statement, $\mathbf{H}_{\mathbf{O 1}}$, from the Asset integrity safety dimension, which states that "there is no significant relationship between Asset Integrity Safety and Adaptation”, is rejected.

Table3. Showing relationship between Asset Integrity Safety and Cohesiveness in the Nigerian Petroleum Industry.

\begin{tabular}{|c|c|c|c|c|}
\hline & & & Assetintergritysafety & Cohesiveness \\
\hline \multirow{6}{*}{$\begin{array}{l}\text { Spearman's } \\
\text { rho }\end{array}$} & \multirow{3}{*}{ Assetintergritysafety } & Correlation Coefficient & 1.000 & 0.498 \\
\hline & & Sig. (2-tailed) & & 0.006 \\
\hline & & $\mathrm{N}$ & 130 & 130 \\
\hline & \multirow{3}{*}{ Cohesiveness } & Correlation Coefficient & 0.498 & 1.000 \\
\hline & & Sig. (2-tailed) & 0.006 & \\
\hline & & $\mathrm{N}$ & 130 & 130 \\
\hline \multicolumn{2}{|l|}{ Decision: } & \multicolumn{3}{|l|}{ Reject $\mathbf{H}_{\mathrm{O} 2}$} \\
\hline
\end{tabular}

Source: Survey data, 2016

Table 3 shows the result of the correlation using the Spearman Rank Correlation Coefficient tool. From the result, it is shown that a significant relationship exists between asset integrity safety and cohesiveness. Asset integrity safety showed a relatively strong positive relationship with cohesiveness, with Rho $(\Upsilon)=0.498$. The relationship is significant at $p=0.006<0.05$ significant level. From this outcome, the hypothesized statement, $\mathbf{H}_{\mathbf{O} 2}$, from the Assetintegritysafety dimension, which states that "there is no significant relationship between Asset Integrity Safety and Cohesiveness", is rejected. 


\section{DISCUSSION OF FINDINGS}

\subsection{Asset Integrity Safety and Adaptation}

The result of the study on the relationship between Asset Integrity Safety and Adaptation showed that, there is indeed a significant relationship between Asset Integrity Safety and Adaptation in the Nigerian Petroleum Industry. Asset Integrity Safety obviously seeks the strategic maintenance of the organisation's installed assets (by its resources) in a healthy state to facilitate the continuity of its business as a 'going concern'. Obviously, the result of this study supports the findings of an earlier study carried out by OHDDC (2008) which opined that, the organisation must first adapt its productive mechanism through its ability to tolerate stress and maintain stability while coping with its organisational challenges. And as already argued, this must be through the ability of the managerial leadership representing the organisational members and the organisation itself to 'mutually tolerate each other' and still carry on the organisation's business to sustain its focus, while simultaneously addressing the challenges of the organisation that may arise from both internal and external demands; in other words, endogenous and exogenous factors. Supporting this view, Simonds \& Grimaldi (1963), Captain-Briggs (1994), Harrison (1994), Charles (1999), Geoff, Kellie \& Roy (2004) and Arora (2007) all maintained that strategic measurement of organisational productivity in terms of its aggregate health, relative to its asset integrity safety practices would be a characteristic review and rating of the content validity and reliability of its occupational health schemes, consistent with tracked operational compliance of the sustained integrity of installed production assets. They further explained that such review will be undertaken relative to the designed (i.e. adapted) organisational safety management standards, in order to verify how effectively they have contended with the foreseen organisational health and safety risks vis-à-vis occupational health risks' mitigation and strategic 'at risk behaviour/tracking of near misses', among others, which are intrinsic in its operations.

\subsection{Asset Integrity Safety and Cohesiveness}

The result of the study on the context relationship between Asset Integrity Safety and Cohesiveness also confirmed that there is indeed a significant relationship between them. The result of this study also agrees with the outcome of an earlier study also carried out by OHDDC (2008) who are of the opinion that, cohesiveness is the state when persons or groups have a clear sense of identity, are attracted to membership, want to stay, and are willing to influence and to be influenced. Similarly, cohesiveness can be seen as the extent to which team members stick together and remain united in the pursuit of a common goal. A team is said to be in a state of cohesion when its members possess bonds linking them to one another and to the team as a whole, in this case, the Asset Integrity Safety team. Members of a highly cohesive team focus on the process, not the person; they respect everyone in the team, assuming good motives; and they fully commit to team decisions and strategies, creating accountability among the team. Morale in cohesive teams is also higher because of increased team member communication, friendly team environment, loyalty and team member contribution in the decision-making process. Successful business strategies are usually carried out by an effective team with a high level of team cohesiveness. Highly cohesive teams are more committed to the goals and activities, are happy when the team succeeds and feel part of something significant, all of which increases self-esteem which, in turn, increases performance.

\section{RECOMMENDATIONS}

The following recommendations serve to assist in fine tuning the context and aggregate perceptions of the contributions of this study. They include:

1. Knowledge adequacy has been canvassed in this study as a strategic necessity for effective predisposition and communication of operational HSE compliance facilitation. This phenomenon is certainly training-based; thus, Top-Management is required to provide the enabling environment via specific and specialized technical training of both the operational personnel and the operational managers to facilitate harmony and synergy between them. This is to ensure that professionals are adequately molded and charged with the responsibility of operating/managing the organisational technical essences.

2. Managing an operational organisation effectively relies heavily on the context preparedness of Top-Management from the perspective of pertinent resource provision. Consequently, the 
sector/industry management must ensure that state-of-the-art operational equipment/gadgets are provided, maintained and personnel trained to man them effectively and efficiently.

3. Managerial role takes responsibility of driving the vision of galvanizing the organisation for effective team work. Top-management therefore, should not be found wanting in this respect, to properly define the mission and craft the vision with absolute clarity so that mischief makers in the clothes of managers are not allowed to misinterpret the organisation's policy direction and cause chaos that shall eventually portend grave dangers for the organisation's sustainability.

4. "Leadership", asserts Richardson (2007), "is cause; every other thing is effect". The leadermanager role is one of the current management themes for strategic management of modern organisations, the Nigerian Petroleum Industry inclusive. From the executive reviews with the industry supervisor's management representatives, the Department of Petroleum Resources (DPR) in the course of this study, it was gathered that the factor of ineffective supervision vis-à-vis dysfunctional industry leadership, is one of the cankerworms feasting on its apparent rot. Thus, by virtue of its strategic industry leadership position, the need for this crop of leader-managers in the Nigerian Petroleum Industry, if we must get it right now, cannot be overemphasized.

5. Effective organisational adaptation and cohesiveness is trusted on team work, which thrives on astute enabling environment to be driven by the team leader or manager. There is therefore, the need for the sector managers, representing the organisation management per se, to provide this environment under which the team members can be allowed to operate in response to the dynamics of the operation so that they take ownership of their responsibilities to manage their individual units effectively and efficiently, instead of groaning and caving under a routine static boss-servant structural weight.

\section{REFERENCES}

[1] Aguh, R. O. K. (2006). "Health, safety and environment (HSE) management in the oil and gas industry - implications of non-compliance"; A seminar paper at the 1st triennial delegates conference of PENGASSAN, NAOC Branch, Port Harcourt.

[2] Allen, N. and Meyer, J. (1990). the measurement and antecedents of affective, normative and continuance commitment to the organization. Journal of occupational psychology, 63(1): 1-18.

[3] Arora, K. C. (2007). Total quality management (Third Edition). New Delhi: S. K. Karia \& Sons Publishers.

[4] Baker, J. A. (2007). The report of the BP U.S. Refineries Independent Safety Review Panel

[5] Barclay, D., Higgins, C. and Thompson, R. (1995). "The partial least squares (PLS) approach to causal modelling: Personal computer adoptation and use as an illustration", Technology Studies, 2(2):285 - 309 .

[6] Baridam, D. M. (2008). Research methods in administrative sciences. Port Harcourt: Sherbrooke Associates.

[7] Captain-Briggs, G. L. (1994). Safety regulations, policies and implementation; Seminar Paper, Nigerian Institute of Safety Professionals (NISP), Port Harcourt.

[8] Charles, A. W. (1999). Safety, health and environmental protection. New York: WCB/McGrawHill.

[9] Chevron Nigeria Limited (CNL, 1997). "Policy 530": Company safety policy document.

[10] Clegg, S., Courpasson, D. \& Philips, N. (2006). Power and organisations, Sage Publications, London.

[11] Cottle, M. K. \& Guidotti, T. M. (1990). Process chemicals in the oil and gas industry: potential occupational hazards. Toxicology and Health, Vol. 6, No. 1; pp.41-56.

[12] Council directive 85/337/eec on the assessment of the effects of certain public and private projects on the environment (1985) from Eur-Lex.

[13] Cummings, T. \& Molloy, E. (1977). Improving productivity and the quality of work life. New York: Praeger.

[14] Department of Petroleum Resources (2002). Environmental guidelines and standards for the petroleum industry in Nigeria [EGASPIN]. Lagos: Federal Government Press.

[15] Department of Petroleum Resources (1997). Oil minerals (safety) regulations [OMSR]. Lagos: Federal Government Press. 
[16] Edward-Odoi, C. A. D. (1996). Cultural determinants of entrepreneurial success - a study of selected entrepreneurs in Rivers State. (Un-published Semester Course Work, University of Port Harcourt).

[17] Edward-Odoi, C. A. D. (1997). An empirical survey of safety regulations' compliance in the Nigerian petroleum industry. B. Sc. Thesis, University of Port Harcourt.

[18] Edward-Odoi, C. A. D. (2006). A Survey of health, safety and environment (HSE) management in the Nigerian petroleum and natural gas industry. MBA Thesis, Enugu State University of Science and Technology, ESUT Business School, Enugu.

[19] Elf Petroleum Nigeria Limited (1997) General safety manual and regulations.

[20] Geoff, T., Kellie, E. \& Roy, H. (2004). Enhancing occupational safety and health. Oxford: Elsevier Butterworth-Heinemann. Guidelines for Risk Based Process Safety, CCPS, 2007.

[21] Haddon, W. (1972). A logical framework for categorizing highway safety phenomena and activity. The Journal of Trauma, 12(3):193-207.

[22] Handy, C. B. (1985). Understanding organizations, 3rd. Edition. Harmondsworth: Penguin Books.

[23] Harrison, L. (1994). Environmental, health and safety auditing handbook (Second Edition). McGraw-Hill Books Publishers: R. R. Donnelly \& Sons Company.

[24] Harrison, R. (1975). "Diagnosing organization ideology", in Jones, J. E. and Pfeiffer, J. W. (Eds), The 1975 Annual Handbook for Group Facilitators, University Associates La Jolla, CA, pp 101-7.

[25] Jain, R. K. \& Rao, S. S. (2009). Industrial safety, health and environment systems (Second Edition). New Delhi: Kanna Publishers.

[26] Nigerian Agip Oil Company Limited (2003). NAOC Health, safety \& environment/quality \& radiation protection (HSE/QR) guide for contractors. Port Harcourt.

[27] Nigerian Agip Oil Company Limited (2005). "HSE competition 2005 Eni E \& P family". Port Harcourt.

[28] Nigerian National Petroleum Corporation and the Federal Ministry of Works \& Housing(1998). The petroleum industry \& the Nigerian environment. Lagos: Obingoz African Holdings Limited, 51 Abayomi Street, Lawanson, Surulere, Lagos.

[29] Nwankwo, A. A. (1982). after oil, what next. (Oil and multinational in Nigeria). Onitsha: Fourth Dimension Publishers B. K.

[30] Okpu, T. \& Kpakol, A.G. (2015) Managing employee trust perceptions for sustained workplace harmony in the Nigerian banking industry. International Journal of Managerial Studies and Research, 3(5): $65-73$.

[31] Organizational Health Diagnostic \& Development Corporation, OHDDC (2008). What is organizational health? At: http://www.organisational health.com/assessment_what.php [accessed January 25, 2015].

[32] Osinuga, L. (1994). "Health, safety and environment practices in modern industrial organizations". B. Sc. Thesis, University of Port Harcourt.

[33] Osuku, P. (1991). Introduction to educational psychology; a lecture note: University of Science \& Technology, Port Harcourt.

[34] Oyolu, O. I. (1993). "Health and safety policies in organisations". B. Sc. Thesis, University of Port Harcourt.

[35] Paul, H. \& Paul, R. (2011). Essentials of environmental management. England: Lavenham Press Limited.

[36] Peters, T. \& Waterman, R. (1982). In search of excellence: lessons from America's best-run companies, New York, NY.

[37] Peters, T. (1999). The circle of innovation. New York: Vintage Books Publishers.

[38] Pittorino, L. A. (2009). the relationship between culture, commitment and performance in a South African Electricity Utility.

[39] Simonds, R. L. \& Grimaldi, J. V. (1963). Safety management: accident cost \& control, (Revised Edition). Homewood, Illinois: Richard D. Irwin, Inc.

[40] Zucker, L. (1987). Institutional theories of organisations, Annual Review of Sociology, 13: 443 64. 